\title{
Models of project activity in the information and educational environment
}

\author{
Inna Tulokhonova ${ }^{1, *}$, and Irina Gluhkova ${ }^{1}$ \\ ${ }^{1}$ East Siberia State University of Technology and Management, 670013, 40B/1 Klyuchevskaya str., \\ Ulan-Ude, Russia
}

\begin{abstract}
One of the priorities of the process of informatization of modern society is the informatization of education. This is the process of ensuring the education sector with the methodology and practice of development, the optimal use of modern information and communication technologies aimed at implementing the goals of state educational policy. This direction of development of the educational industry, as emphasized in government documents, is recognized as the most important national priority. At the same time, the creation of optimal conditions for the productive activities of the subjects of the educational process is a complex task, causing the design and development of the subject informational and educational environment, as an opportunity for a comprehensive and concrete solution of the training tasks and the form of organization of the effective activities of its subjects. At the same time, the existence of procedures and rules governing the joint activity of subjects and its organization is a basic feature of the system that determines the order of an activity and the mechanism of its operation. In addition to the mechanism of operation, we can distinguish the mechanism of management as a set of procedures for making management decisions. The authors of this work consider project activity as a particular task of designing the activity itself and the dynamic system of interaction of the subject with the world in general, and the realization of the mediated relations of the subject in objective reality in particular, acting on the controlled system in order to ensure the required behaviour. The article presents the results of the development of models of project activities, organizing the process of learning management in the subject information and educational environment of the university.
\end{abstract}

\section{Introduction}

In recent decades, many new concepts have arisen in the educational sciences, which are in fairly complex and sometimes contradictory relations with the traditional apparatus of pedagogy. This process is updated in connection with the policy of modernization and global trends, including the introduction of new economic and legal mechanisms for managing education, expanding international cooperation in the field of education,

\footnotetext{
* Corresponding author: ISTulokhonova@ mail.ru
} 
strengthening the role of information and communication technologies in the legislative sphere of domestic education. So, for example, in the second chapter of the "Concept of modernization of Russian education for the period until 2020", devoted to the priorities of educational policy, the following is said: "In order to achieve a new quality of education, education will be computerized, including the optimization of teaching methods".

Information and communication technologies have created a fundamentally new information educational environment, which is a means for individual and collective learning in traditional, distance and mixed forms of education, which creates favorable conditions for group productive activities and is an effective mechanism for the timely transmission of information, as well as a necessary condition for development information, improving the general and professional culture of both students and teachers high school.

\section{Problem Statement}

\subsection{Informational and educational environment}

Various aspects of the informational and educational environment, methods and approaches to its modeling are the research subjects for both fundamental and applied sciences. On the basis of the works $[3,5,6$, et al.], it can be said that the authors differ in the number of elements included in the definition of the informational and educational environment, but a number of its components are described by them with a sufficient degree of stability: subjects, information and communication tools, ways of interaction.

A separate issue is the relationship between the concept of "informational and educational environment" and the related concepts of "educational environment", "educational space", "information environment", etc. The common interpretation of them is that they mean the system aggregates that provide organization educational process, however, the differences between these concepts are no less significant.

In modern conditions, the concept of the educational environment naturally integrates into itself the unique opportunities provided by information, telecommunication and distance technologies. At the same time, the concept of "informational educational environment" is multivalued.

The concept of an informational and educational environment is understood by us as a set of subjects, their educational needs, communicative relations and informational models, immersed in the context of the global informational and social environment, ensuring a holistic process of personal development aimed at productive activities, is one of the important concepts for our research. Excessive technocracy of the informational and educational environment has already become the subject of rethinking in a number of studies (A. A. Andreev, Y. S. Branovsky, J. N. Zaitseva, I. G. Zakharova, V. I. Soldatkin, V. A. Yasvin and others), supplementing these definitions by clarifying the organizational aspects of pedagogical interaction. This allowed to cover the characteristic features of the environment with sufficient accuracy, which the authors denote by the term "informational and educational environment".

Therefore, it seems obvious to us that qualitative modeling of the informational and educational environment in its objective context and organization of activities is possible mot only in relation to theoretical and methodological foundations of the application of information and communication technologies in education, but also in the field of problems of productive activity of the subjects of educational interaction.

The subject context of the informational and educational environment is not only of equal importance but acquires a contour of advanced education, both in terms of defining the content of education, generating new ideas and improving the teaching methodology, 
which is focused on improving the preparedness of a university graduate. Consequently, the subject informational and educational environment should be aimed at stimulating creative activity, improving the content of training and issues of interpersonal dialogue and personal self-realization of the participants of educational interaction as the most essential conditions for the development of competencies and competences in the whole process of training.

Thus, considering the student's project activity as a particular task of designing the activity itself and the system of organization and management in the subject informational educational environment, it is necessary to build a dynamic model of the learning management system in order to determine the reachability of a certain system level and sequence of events leading the system to a given state of the student's activity.

\subsection{Models of the organization of project activities in the educational process}

The solution of the tasks of designing the organization of activities and their management in the socio-economic sphere, including education, is based on theoretical and applied studies of systemic links and patterns of functioning and development of objects / subjects and processes in society. During the period of intensification and computerization of the education sector, as well as the comprehensive automation of the learning process in the educational system, there is a problem of managing the educational process as the organization and implementation of effective activities of participants in the educational process.

Project activities in the informational and educational environment are aimed at solving certain problems in a specific subject area. Each problem, in turn, as an information object, is always dynamic, having a beginning, a process of development and completion, i.e. own "life cycles." The subjects' activities are aimed at managing the development of the problem until achieving the goal defined in the problem.

\section{Research Questions}

\subsection{Models of project activities in the subject-educational environment}

The organization of project activities is based on an iterative model of activity. This organization of activity is convenient because the goal is achieved gradually. At each phase of the project activity, a prototype (alternative) of the product of the activity (solution) is developed.

The research phase: this phase organizes activities in the cognitive sphere and in the real environment. Information resources are established on the topic of the problem (knowledge) and especially analogues of the problem being solved. The goal of work in this phase is to collect and formalize all resources to solve the problem posed.

The refinement phase: the problem is detailed to specific tasks, formalized in the cognitive sphere and presented as a virtual or real environment.

The activity construction phase for the formalized description of the problem: the construct of the problem-solving method is built and on the basis of this construct in a real (virtual) environment an algorithm (technology) of the problem-solving method or the toolsolution construct is built. The goal of work in this phase is to build an effective problem solution construct.

The verification phase: Verifies the operability and effectiveness of the found solution construct in a real environment. If the construct's effectiveness is questionable, then all phases of the activity are repeated with the involvement of new resources. 
When analyzing technologies of project activities, several design models are considered (E. S. Pollat, E. V. Petukhova, L. N. Zhurbenko, etc.). Despite the fact that there is no single algorithm for project activity, the following areas of project activity are reflected in all models to one degree or another.

As part of an iterative activity model, the design process consists of several stages, with the possibility of refining and evaluating the design work. Gradual submission of the subject material, the formation and distribution of roles in the group, the purpose of the work is determined, the problem that requires a specific solution (preparation) is identified. A project plan, model, formal description of the problem, hypothesis, the choice of method for solving the problem (planning) are developed.

Pre-created models are discussed and adjusted. According to the results of the planning stage, an algorithm for the solution and its implementation (research) are being developed. The analysis of the work is done within the working group, including the preparation of a report (analysis and synthesis), the presentation of the finished work and the assessment of the result and work process (assessment).

The algorithm of the activities of the participants of the design process at its stages, taking into account the phase space, is shown in Table 1.

Table 1. Phased model of project activities.

\begin{tabular}{|c|c|c|c|}
\hline \multirow{2}{*}{$\begin{array}{l}\text { Algorithm } \\
\text { activities }\end{array}$} & \multicolumn{2}{|c|}{ Phase space } & \multirow{2}{*}{ Design stages } \\
\hline & Cognitive sphere & Real sphere & \\
\hline $\begin{array}{l}\text { Preparation and } \\
\text { submission of material }\end{array}$ & \multirow{8}{*}{$\begin{array}{l}\text { Phase of problem } \\
\text { formalization and } \\
\text { identification of its } \\
\text { solution }\end{array}$} & \multirow{4}{*}{ Beginning the research } & \multirow{3}{*}{ Training } \\
\hline Group formation & & & \\
\hline Role distribution & & & \\
\hline Identify the problem & & & \multirow{9}{*}{ Planning } \\
\hline $\begin{array}{l}\text { Formal problem } \\
\text { description }\end{array}$ & & \multirow{4}{*}{ Refinement phase } & \\
\hline Domain analysis & & & \\
\hline Hypothesis & & & \\
\hline $\begin{array}{l}\text { Determination of } \\
\text { solution }\end{array}$ & & & \\
\hline Project plan & \multirow{4}{*}{$\begin{array}{l}\text { Phase of work on the } \\
\text { construction of } \\
\text { solutions to the } \\
\text { problem }\end{array}$} & \multirow{4}{*}{ Activity planning phase } & \\
\hline Model construction & & & \\
\hline $\begin{array}{l}\text { Creating a solution } \\
\text { algorithm }\end{array}$ & & & \\
\hline $\begin{array}{l}\text { Approving the plan, } \\
\text { models, algorithm }\end{array}$ & & & \\
\hline $\begin{array}{l}\text { Solving or } \\
\text { investigating a } \\
\text { problem }\end{array}$ & $\begin{array}{c}\text { Phase of } \\
\text { implementation of } \\
\text { problem solving }\end{array}$ & \multirow{6}{*}{ Verification phase } & Study \\
\hline Generalization & & & \multirow{3}{*}{$\begin{array}{l}\text { Analysis and synthesis } \\
\text { of work, making an } \\
\text { informed decision }\end{array}$} \\
\hline Analysis of the work & & & \\
\hline $\begin{array}{l}\text { Presentation } \\
\text { preparation }\end{array}$ & & & \\
\hline $\begin{array}{l}\text { Presentation of the } \\
\text { product or work done }\end{array}$ & & & Project presentation \\
\hline $\begin{array}{l}\text { Evaluation of the } \\
\text { result and process }\end{array}$ & & & $\begin{array}{l}\text { Evaluation of the result } \\
\text { and process }\end{array}$ \\
\hline
\end{tabular}


Thus, the imposition of the organization of work on the systemic methodology of productive didactics and the model of iterative development of the project life cycle allows organizing project activities in the educational process aimed at creative orientation, taking into account the need to revise, refine and evaluate project decisions, stimulating active interaction between the project team.

The project activity in the educational process represents a dynamic process of interaction and, accordingly, can be described by modeling methods corresponding to the concept of interaction. In accordance with the model of the design training process, the final stage evaluates the results of educational activities based on test control, a personal indicator of the level of readiness for project activities and an integral indicator of achievement of the level of project competence.

\subsection{Project activities as a task of managing activities in the subject informational and educational environment of the university}

Project activities in the educational process of the university, as a particular task of managing activities in the subject area and one of the methods ensuring the system integration of scientific knowledge and practical actions, is a resultant indicator of the function of several variables (management) [5].

Analysis of trends in the formation and development of project activities in the subject informational and educational environment shows that in order to best recover from the initial statistical data of the conditional value of the resulting indicator $y(x)$ and the unknown regression function $f(x)=M(y / x)$, the most frequently used adequacy criteria presented in [9] are insufficient. Disadvantages of this kind are manifested both in the transfer of the design object and in the transition of the subject of activity from one environment to another.

By virtue of this, for a holistic view of the design process, it is necessary to consider a set of $\langle O, U, P R, S\rangle$, where $O$ is an object; $U$ is the subject; $P R$ is a design process consisting of several stages; $S$ - the informational and educational design of the environment. The result of the design is the display of the subject at its various stages.

Omitting the argument, it can be argued that to maintain a holistic display of project activities in an information and educational environment, the design process should be considered, highlighting the following management mechanisms:

- Sequence of displaying the states of the subject in the U (O, PR) design environment;

- The sequence of events leading to a targeted change in the states of the subject

- Design in the process of intellectual activity PR (U, S);

- Decision-making mechanism in assessing the state of $U(O, S)$ and the choice of the elements $P R\left(U, S\left(P r_{i}\right)\right), i=1, \ldots, n$.

From the standpoint of control operations performed by the informational educational design environment, the $P R$ process $\left(U, S\left(P r_{i}\right)\right.$ is transformed into the PR process $(I, U, S$ $\left(\operatorname{Pr}_{i}, F\right)$. Here, $I$ means interactive definitions of the subject $U$, respectively $F$, is some managerial conversion function. The model of a dedicated project procedure can be represented as the following tuple

Many of the project data:

$$
M_{i}=\{D, P, F, T\}
$$

$$
\begin{gathered}
D=\left\{d_{i} \mid i=0 \ldots n-1, d_{i} \in a D\right\} \\
\left.P=\left\{p_{i}\left(D_{i} U_{i}\right) \mid \begin{array}{c}
i=0 \ldots m-1, p_{i} \in a P, D_{i} \subset D, U_{i}=\left\{u_{j} \mid j=1 \ldots r, u_{j} \in a U\right\} \\
F=\{f i \mid
\end{array}\right\}=0 \ldots k-1, f i \in a F\right\}
\end{gathered}
$$

where $T$ stands for the processes occurring in the managing project procedure. 
A similar control mechanism can be the Petri Net, which simulates this process of activity.

\subsection{Modeling the project activities in the informational and educational environment at a university}

The study of the properties of Petri Nets in the simulation of dynamic systems determines the analysis of the level of reachability of the system to internal and external conditions in order to control and manage it. Petri Net, as a bipartite oriented graph, the set of vertices that is divided into two subsets and where there is no arc connecting two vertices from one subset. Formally, in terms of systems theory, it represents a set of elements (the tuple) $N=$ $\{T, P, A\}$, where $T=\left\{t_{1}, t_{2}, \ldots, t_{n}\right\}$ is a non-empty set of elements called transitions; $P=\left\{p_{1}\right.$, $\left.p_{2}, \ldots, p_{m}\right\}$ is a non-empty set of elements called positions. The sets of positions and transitions do not intersect $T \cap P=\varnothing ; A \subseteq(T \times P) U(P \times T)$ is the set of oriented arcs.

By definition, an arc connects either a position with a transition or a transition with a position. The network status at each current time is determined by the condition system. In order to make it possible and convenient to set a condition like "there are 3 records in the buffer", chips are added to the Petri Net model. Chips are represented by dots inside the place.

For the particular case, the model of project management in the subject environment is shown in Figure 1.

The main positions of $P_{m}, P_{d}, P_{t}, P_{j}, P_{s}, P_{e}, P_{f}$ model the external conditions in relation to the educational process: $P_{m}$ - the base of materials developed by the group in the process of analysis and planning, $P_{d}$ - the base of resources, $P_{t}$ - the base of test materials, $P_{p}$ - the base of the themes of the design work, $P_{j}-$ the archive of the projects, $P_{s}$ - the learner is present, $P_{e}$ - the learning system is free, $P_{f}$ - the project is completed. The main transitions should be attributed to the $t_{S}-$ the student enters the system, $t_{f}-$ the student leaves the system.

Internal conditions modeled by positions:

$P_{1}$ - training is possible, assessment of the student's abilities is made; $P_{2}$ - a project theme is selected; $P_{3}-$ design participants' interaction is possible; $P_{4}-$ a discussion is completed; $P_{5}-$ a group decision is made, participants are ready for new interactions; $P_{6}-$ the main problem was identified, the design goal was set; $P_{7}-$ the solution is determined; $P_{8}-$ a project plan, a solution algorithm, project models; $P_{9}-$ the work has been completed; $P_{10}-$ the analysis of the work done has been completed and the work has been summarized; $P_{11}-$ the answer has been evaluated; $P_{12}-$ a project is completed.

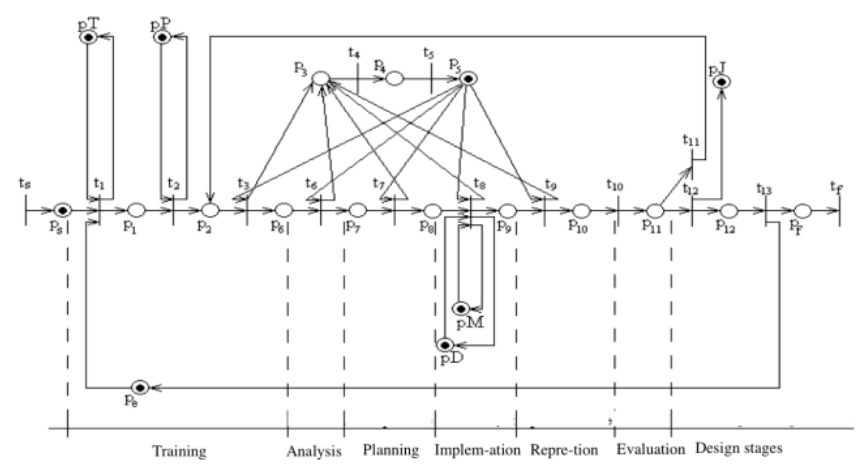

Fig. 1. Petri Net modeling. 


\subsection{Fuzzy conclusion and assessment of students' project competence}

Consider the following most commonly used modifications of the fuzzy inference algorithm, assuming, for simplicity, that the knowledge base is organized by two fuzzy rules of the form:

$$
\begin{aligned}
& P R_{1}:\left\{I F x_{1} \text { is } A_{11} \ldots A N D \ldots x_{n} \text { is } A_{l n} \text { THEN } y \text { is } B_{1}\right\} \text { or } \\
& P R_{2}:\left\{I F x_{1} \text { is } A_{11} \ldots A N D \ldots x_{n} \text { is } A_{l n} \text { THEN y is } B_{2}\right\} \text { or } \\
& P R_{m}:\left\{I F x_{1} \text { is } A_{11} \ldots A N D \ldots x_{n} \text { is } A_{l n}, \text { THEN y is } B_{m}\right\},
\end{aligned}
$$

where $x$ and $y$ are the names of input variables; $z$ is the name of the output variable; $A_{11}$, $A_{1 n}, B_{1}, B_{2}, B_{m}$ are some of the specified membership functions, with a clear value of $\mathrm{z}$ to be determined on the basis of the information provided and clear values of $x_{0}$ and $y_{0}$.

A set of fuzzy rules represents the base of rules for calculating the evaluation of a trainer.

$$
\begin{aligned}
& \mathrm{PR}_{1}:\left\{\mathrm{IF} \mathrm{x}_{1} \text { это } \mathrm{A}_{11} \text { AND } \mathrm{x}_{2} \text { is } \mathrm{A}_{21} \text {, THEN } \mathrm{y} \text { is } \mathrm{B} 1\right\} \text { or } \\
& \mathrm{PR}_{2}:\left\{\text { IF } \mathrm{x}_{1} \text { это } \mathrm{A}_{11} \text { AND } \mathrm{x}_{2} \text { is } \mathrm{A}_{22} \text {, THEN } \mathrm{y} \text { is } \mathrm{B}_{2}\right\} \text { or } \\
& \mathrm{PR}_{3} \text { : }\left\{\text { IF } \mathrm{x}_{1} \text { это } \mathrm{A}_{11} \text { AND } \mathrm{x}_{2} \text { is } \mathrm{A}_{23} \text {, THEN } \mathrm{y} \text { is } \mathrm{B}_{3}\right\} \text { or } \\
& \mathrm{PR}_{4}:\left\{\mathrm{IF}_{1} \text { это } \mathrm{A}_{11} \text { AND } \mathrm{x}_{2} \text { is } \mathrm{A}_{24} \text {, THEN } \mathrm{y} \text { is } \mathrm{B}_{4}\right\} \text { or } \\
& P_{5}:\left\{\text { IF } x_{1} \text { это } A_{12} \text { AND } x_{2} \text { is } A_{21} \text {, THEN } y \text { is } B_{5}\right\} \text { or } \\
& \mathrm{PR}_{6}:\left\{\text { IF } \mathrm{x}_{1} \text { это } \mathrm{A}_{12} \text { AND } \mathrm{x}_{2} \text { is } \mathrm{A}_{22} \text {, THEN } \mathrm{y} \text { is } \mathrm{B}_{6}\right\} \text { or } \\
& \mathrm{PR}_{7}:\left\{\mathrm{IF}_{1} \text { это } \mathrm{A}_{12} \mathrm{AND}_{2} \text { is } \mathrm{A}_{23} \text {, THEN } \mathrm{y} \text { is } \mathrm{B}_{7}\right\} \text { or } \\
& \mathrm{PR}_{8}:\left\{\text { IF } \mathrm{x}_{1} \text { это } \mathrm{A}_{12} \text { AND } \mathrm{x}_{2} \text { is } \mathrm{A}_{24} \text {, THEN } \mathrm{y} \text { is } \mathrm{B}_{8}\right\} \text { or } \\
& \mathrm{PR}_{9}:\left\{\mathrm{IF}_{1} \text { это } \mathrm{A}_{13} \mathrm{AND}_{2} \text { is } \mathrm{A}_{21} \text {, THEN } \mathrm{y} \text { is } \mathrm{B}_{9}\right\} \text { or } \\
& \mathrm{PR}_{10} \text { : }\left\{\text { IF } \mathrm{x}_{1} \text { это } \mathrm{A}_{13} \text { AND } \mathrm{x}_{2} \text { is } \mathrm{A}_{22} \text {, THEN } \mathrm{y} \text { is } \mathrm{B}_{10}\right. \text { or } \\
& \mathrm{PR}_{11} \text { : }\left\{\mathrm{IF}_{1} \text { это } \mathrm{A}_{13} \text { AND } \mathrm{x}_{2} \text { is } \mathrm{A}_{23} \text {, THEN } \mathrm{y} \text { is } \mathrm{B}_{11}\right\} \text { or } \\
& \mathrm{PR}_{12} \text { : }\left\{\mathrm{IF}_{1} \text { это } \mathrm{A}_{13} \text { AND } \mathrm{x}_{2} \text { is } \mathrm{A}_{24} \text {, THEN } \mathrm{y} \text { is } \mathrm{B}_{12}\right\} \text {. }
\end{aligned}
$$

Accordingly, we have $P R_{m}$ - fuzzy rules, $x_{k}, k=1 \ldots n$ - input variables, $y$ - output variables, $A_{i k}$ - specified fuzzy sets with membership functions, and the "IF" part is a statement about the linguistic meaning of input variables, the initial level of the design competences, and the part "THEN" is a statement about the corresponding value of the current level of project competence. Often, each premise contains statements about the four input variables, connected by the "AND" union.

To derive a fuzzy assessment of the student, we use the Fuzzy command of the Mat Lab Fuzzy Logic interface program package and direct methods for determining the membership function for each $x € P R$.

The parameters of the membership functions of the student's variable characteristics are shown in the Figure 2.
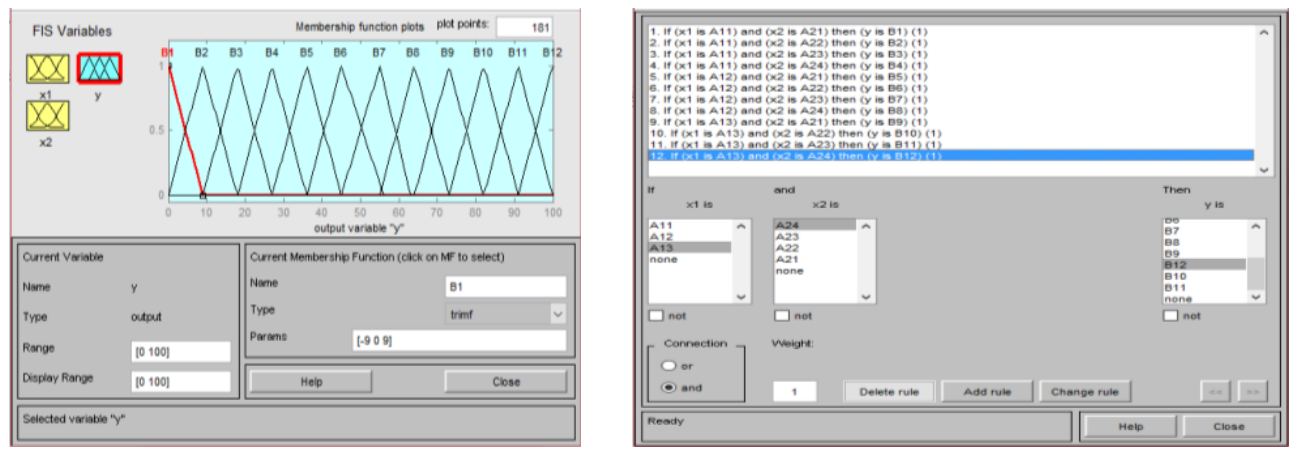

Fig. 3. The fuzzification / fuzzy inference procedure. 
Based on the fact that any integral indicator summarizes all local indicators in the subject area, including temporary, situational, local assessments of components of the development of project activities made on the basis of repeated measurements can serve as criteria for evaluating components of project competence.

\section{Purpose of the Study}

Knowledge management in the learning process occupies an important place. In accordance with the qualitative changes in the target and value systems, both the education system as a whole and the subjects of the educational process in particular, not so much of the accumulation of information arrays is of great importance, but the ability to transform information on the basis of its structuring and systematization, leading to the effective absorption of knowledge subject area.

The aim of the study is to develop models of project activities in the subject information and educational environment, which are aimed at productive activities in the provision and management of the educational process in the higher education system, as s well as checking their efficiency and effectiveness in the experimental work.

\section{Research Methods}

We used the mathematical apparatus for generalizing classical logic, the methodology for analyzing temporal stochastic Petri nets in the study and modeling of the dynamics of project activities in the process of studying a training course and finding the limit distribution of probabilities of attainable markings.

The methodological basis of the research is the philosophical concepts of the humanization of education (A. Maslow, R. May, C. Rogers, V. Frankl, E. Fromm); conceptual and methodological foundations in the development of modern educational technologies (G. K. Selevko, V. P. Bespalko, V. M. Monakhov); theoretical foundations of informatization of education and the use of information technologies in the education system (A. A. Andreev, V. I. Soldatkin, I. G. Zakharova, S. N. Pozdnyakov, S. I. Maslov, E. S. Polat, I. V. Robert, A. V. Khutorskaya); elements of cognitive psychology (R. Gagne, J. Bruner, U. Naisser, B. U. Takman) and psychology of computerization (E. I. Mashbits, P. I. Obraztsov, O. K. Tikhomirov); methodological foundations of the design and use of information environments in education (I. G. Zakharova, N. A. Reznik, V. Yu. Belkin, K. I. Kostenko, A. B. Kurgan, B. Ye. Levitsky, etc.); the development of project activities in educational practice (N. Yu. Bugakova, N. K. Nuriev and others); problems of creativity (A. I. Polovinkin, Y. A. Ponomarev, V. V. Popov); fundamentals of technology modeling and development of educational electronic resources (A. I. Bashmakov, I. A. Bashmakov, G. A. Dorrer, G. M. Rudakova, etc.); technological and methodological foundations of the transition to competence-based models of formation and evaluation of the results of educational activities (V. I. Baidenko, V. A. Bolotov, I. A. Zimnyaya, G. A. Larionova, D. Raven, V. V. Serikov, Yu. G. Tatur, A.V. Khutorskaya and others.).

\section{Findings}

\subsection{Model of the project activity of the learning process}

A visual representation of the dynamics of project activities at each stage of the creation of an educational project provides an approach using a methodology for modeling the dynamics of discrete systems based on the formalism of Petri nets. 
An example of a project activity protocol in the course learning process and transition, triggering the rules in terms of "condition-action" are shown in Figure 3.

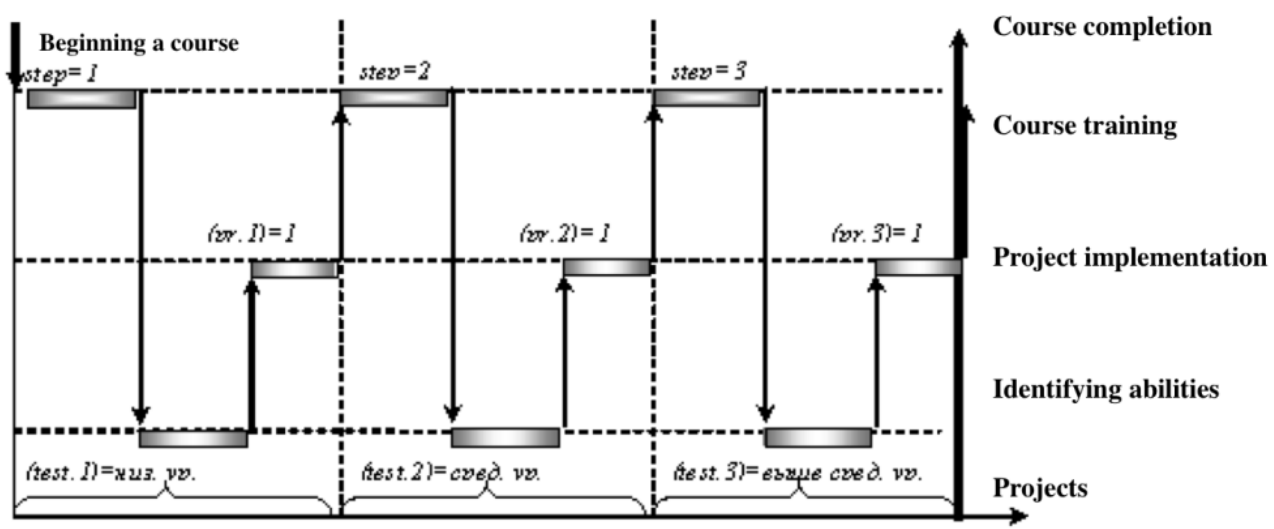

Fig. 3. The project activity protocol in the course study process.

The rules for triggering transitions in terms of the "condition - action" axis are presented in Table 2.

Table 2. The Petri network triggering rules.

\begin{tabular}{|c|c|}
\hline Transition & Transition triggering rules \\
\hline 1 & 2 \\
\hline $\mathrm{t}_{1}$ & $\begin{array}{l}\text { If }(\mu(\mathrm{pe})=1 \text { and } \mu(\mathrm{ps}) \geq 1 \text { and } \mu(\mathrm{pT}) \geq 1) \text { then }(\mu(\mathrm{p} 1)=1 \text { and } \mu(\mathrm{pe})=0 \text { and } \mu(\mathrm{ps}) \\
=\mu(\mathrm{ps})-1 \text { and } \mu(\mathrm{pT})=\mu(\mathrm{pT}))\end{array}$ \\
\hline $\mathrm{t}_{2}$ & If $(\mu(\mathrm{p} 1)=1$ and $\mu(\mathrm{pP}) \geq 1)$ then $(\mu(\mathrm{p} 2)=1$ and $\mu(\mathrm{p} 1)=0$ and $\mu(\mathrm{pM})=\mu(\mathrm{pP}))$; \\
\hline$t_{3}$ & If $(\mu(\mathrm{p} 2)=1$ and $\mu(\mathrm{p} 5)=1)$ then $(\mu(\mathrm{p} 3)=1$ and $\mu(\mathrm{p} 2)=0$ and $\mu(\mathrm{p} 6)=1$ and $\mu(\mathrm{p} 5)=0)$; \\
\hline $\mathrm{t}_{4}$ & If $(\mu(\mathrm{p} 3)=1)$ then $(\mu(\mathrm{p} 4)=1$ and $\mu(\mathrm{p} 3)=0)$; \\
\hline$t_{5}$ & If $(\mu(\mathrm{p} 4)=1)$ then $(\mu(\mathrm{p} 5)=1$ and $\mu(\mathrm{p} 4)=0)$; \\
\hline $\mathrm{t}_{6}$ & If $(\mu(\mathrm{p} 5)=1$ and $\mu(\mathrm{p} 6)=1)$ then $(\mu(\mathrm{p} 7)=1$ and $\mu(\mathrm{p} 3)=1$ and $\mu(\mathrm{p} 5)=0$ and $\mu(\mathrm{p} 6)=0)$; \\
\hline $\mathrm{t}_{7}$ & If $(\mu(\mathrm{p} 5)=1$ and $\mu(\mathrm{p} 7)=1)$ then $(\mu(\mathrm{p} 8)=1$ and $\mu(\mathrm{p} 3)=1$ and $\mu(\mathrm{p} 5)=0$ and $\mu(\mathrm{p} 7)=0)$; \\
\hline $\mathrm{t}_{8}$ & $\begin{array}{l}\text { If }(\mu(\mathrm{p} 8)=1 \text { and } \mu(\mathrm{pM}) \geq 1 \text { and } \mu(\mathrm{pD}) \geq 1) \text { then }(\mu(\mathrm{p} 9)=1 \text { and } \mu(\mathrm{pM})=\mu(\mathrm{pM}) \text { and } \\
\mu(\mathrm{pD})=\mu(\mathrm{pD}) \text { and } \mu(\mathrm{p} 8)=0)\end{array}$ \\
\hline$t_{9}$ & $\begin{array}{l}\text { If }(\mu(\mathrm{p} 5)=1 \text { and } \mu(\mathrm{p} 9)=1) \text { then }(\mu(\mathrm{p} 10)=1 \text { and } \mu(\mathrm{p} 3)=1 \text { and } \mu(\mathrm{p} 5)=0 \text { and } \mu(\mathrm{p} 9) \\
=0) ;\end{array}$ \\
\hline $\mathrm{t}_{10}$ & If $(\mu(\mathrm{p} 10)=1)$ then $(\mu(\mathrm{p} 11)=1$ and $\mu(\mathrm{p} 10)=0)$ \\
\hline $\mathrm{t}_{11}$ & If $(\mu(\mathrm{p} 11)=1)$ then $(\mu(\mathrm{p} 2)=1$ and $\mu(\mathrm{p} 11)=0)$ \\
\hline $\mathrm{t}_{12}$ & If $(\mu(\mathrm{p} 11)=1)$ then $(\mu(\mathrm{p} 12)=1$ and $\mu(\mathrm{pJ})=\mu(\mathrm{pJ})+1$ and $\mu(\mathrm{p} 11)=0)$; \\
\hline $\mathrm{t}_{13}$ & If $(\mu(\mathrm{p} 12)=1)$ then $(\mu(\mathrm{pe})=1$ and $\mu(\mathrm{pf})=1$ and $\mu(\mathrm{p} 12)=0)$. \\
\hline
\end{tabular}




\subsection{Evaluating project activities in the subject information educational environment}

Evaluation criteria that determine the degree of student's readiness for project activities at the beginning and end of a certain design period are presented in Tables 3-4.

Students who studied the course in experimental methods had statistically significant results. This result directly reflects the indicators of the project-activity component at the design stages (Table 3).

Table 3. Main characteristics of determining the level of students' project competence (projectactivity component).

\begin{tabular}{|l|c|c|c|c|}
\hline \multicolumn{1}{|c|}{ Project activity component } & \multicolumn{2}{|c|}{ Control } & \multicolumn{2}{c|}{ Experimental } \\
\cline { 2 - 5 } & $\begin{array}{c}\text { at the } \\
\text { beginning }\end{array}$ & in the end & $\begin{array}{c}\text { at the } \\
\text { beginning }\end{array}$ & in the end \\
\hline $\begin{array}{l}\text { 1. Synthesis of knowledge from } \\
\text { various projects }\end{array}$ & - & - & - & + \\
\hline $\begin{array}{l}\text { 2. Logical analysis and synthesis } \\
\text { of elements of structural, } \\
\text { functional and system analysis }\end{array}$ & - & - & - & + \\
\hline $\begin{array}{l}\text { 3. Simulation of various processes } \\
\text { based on the methods of } \\
\text { computational, graphical, system, } \\
\text { critical analysis }\end{array}$ & - & + & + & + \\
\hline $\begin{array}{l}\text { 4. Possession of optimization, } \\
\text { prognostic, heuristic and } \\
\text { Decision-analysis methods }\end{array}$ & - & + & + & + \\
\hline $\begin{array}{l}\text { 5. Ability to use information and } \\
\text { communication technologies in } \\
\text { design }\end{array}$ & - & + & + & + \\
\hline $\begin{array}{l}\text { 6. Possession of computerized } \\
\text { methods of collecting, storing and } \\
\text { processing information }\end{array}$ & + & + & + & + \\
\hline $\begin{array}{l}\text { 7. Creative search in design } \\
\text { theory }\end{array}$ & - & - & + & + \\
\hline $\begin{array}{l}\text { 8. Independent project } \\
\text { development }\end{array}$ & - & - & - & + \\
\hline $\begin{array}{l}\text { 9. Development of } \\
\text { interdisciplinary projects }\end{array}$ & - & - & - & + \\
\hline $\begin{array}{l}\text { 10. Awareness of personal } \\
\text { responsibility for the results of } \\
\text { their activities }\end{array}$ & - & + & + \\
\hline $\begin{array}{l}\text { 11. Intellectual and creative } \\
\text { activity }\end{array}$ & - & & + \\
\hline
\end{tabular}

To determine the level of project competence and evaluation of educational activities (Figure 4), a number of criteria for the development of the subject material were formulated and tested. 


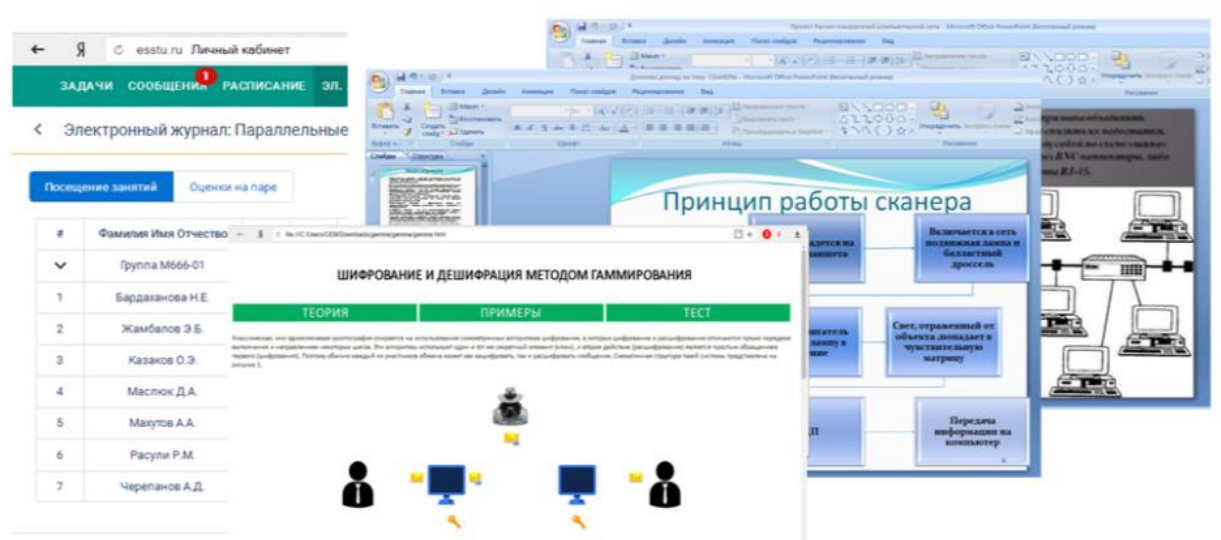

Fig. 4. Project evaluation in the subject informational and educational environment of the university.

Key indicators that are adequate to the assessment of project work in achieving the goals of the activities and the compliance with the selected goals are shown in Table 4.

Table 4. Criteria for evaluating project work.

\begin{tabular}{|l|l|l|l|}
\hline $\begin{array}{c}\text { The main criteria for } \\
\text { evaluating project work }\end{array}$ & \multicolumn{2}{|c|}{ Evaluation method } & \multicolumn{1}{|c|}{$\begin{array}{c}\text { Match the selected } \\
\text { target }\end{array}$} \\
\hline Degree of creativity & Expert & Expert & $\begin{array}{l}\text { Compliance with the } \\
\text { "start" direction }\end{array}$ \\
\hline Professionalism & Expert & Expert & $\begin{array}{l}\text { Satisfaction with } \\
\text { limitations }\end{array}$ \\
\hline Labor intensity & $\begin{array}{l}\text { Operational and } \\
\text { Technological } \\
\text { Expert Method for } \\
\text { Applied Systems } \\
\text { Analysis }\end{array}$ & Expert & $\begin{array}{l}\text { The adequacy of the } \\
\text { implementation } \\
\text { according to the "final" } \\
\text { direction }\end{array}$ \\
\hline Practical value & Expert & Expert & $\begin{array}{l}\text { Result aimed at } \\
\text { productive creative } \\
\text { activity }\end{array}$ \\
\hline
\end{tabular}

\section{Conclusion}

The methodological approach chosen in the study allowed to build models of project activities in the educational process from the point of view of their system integration into the information and educational environment of the university.

On the basis of the system of models presented in the work, the methodology for the formation of project activities was developed and tested on the subject material of the disciplines "Computer modeling," "Information systems," "Web-design," for students of various forms of training and training areas of the East-Siberian State University of Technology and Management.

Taking into account the characteristics of the organization of educational activities in the subject information and educational environment of project activities, this methodology, provides:

- Support for personalized subject environments in the framework of the student-centered principle of organizing educational activities; 
- Development, implementation, and maintenance of information and educational resources in the system of educational and methodical work at a university as a comprehensive project of information technology support and management of educational activities;

- Assessment of project competence as a qualitative characteristic of a student in solving problems of training a competent specialist, taking into account the competence approach.

\section{References}

1. I. R. Abdulmyanova, Tomsk State Pedagogical University Bulletin, 2, pp. 36-39 (2010)

2. A. I. Artyukhina, N. V. Ivanova, Architecture, construction, ecology: program, reports and reports of the Intern. seminar, Barcelona, Spain, May 18-25, 2002, pp. 100-101 (Barcelona, 2002)

3. A. A. Andreev, V. I. Soldatkin, Applied Open Education Philosophy: Pedagogical Aspect (RIC "Alpha"; MGOPU them. M. A. Sholokhov, Moscow, 2002)

4. V. I. Bogoslovsky, V. A. Izvozchikov, M. N. Potemkin, Science in the pedagogical university: questions of methodology, theory and practice (Publishing House of the St. Petersburg Iniversity, Saint Petersburg, 2000)

5. E. V. Demina, Professional Education in Russia and Abroad, 1, 17, pp. 96-101 (2015)

6. A. A. Dobryakov, Creating a unified information space of the education system: seminar materials (Research Center for Problems of Quality Training, Moscow, 1998)

7. D. A. Novikov, N. P. Glotova, Models and mechanisms for managing educational networks and complexes, pp. 14-27 (Institute of Education Management of the Russian Academy of Education, Moscow, 2004)

8. N. K. Nuriev, Didactic training space for competent specialists in software engineering (Kazan University Press, Kazan, p. 244, 2005)

9. N. I. Pak, Projective approach to learning as an information process (Publishing House of the KSPU them. V. P. Astafieva, Krasnoyarsk, 2008)

10. I. S. Tulokhonova, Informatization of eEducation and Science, 2, 10, pp. 14-27, (2011)

11. I. S. Tulokhonova, Scientific and methodological foundations of the formation of the project activities of students in the subject information and educational environment (VSGUTU, Ulan-Ude, p. 190, 2009) 